\title{
The Influence of Polyunsaturated Fatty Acids on the Phospholipase D Isoforms Trafficking and Activity in Mast Cells
}

\author{
Shereen Basiouni ${ }^{1,2}$, Herbert Fuhrmann ${ }^{1}$ and Julia Schumann ${ }^{1, *}$ \\ 1 Institute of Physiological Chemistry, Faculty of Veterinary Medicine, University of Leipzig, \\ Leipzig, An den Tierkliniken 1, 04103 Leipzig, Germany; \\ E-Mails: basiouni@vmf.uni-leipzig.de (S.B.); fuhrmann@vmf.uni-leipzig.de (H.F.) \\ 2 Department of Clinical Pathology, Faculty of Veterinary Medicine, Benha University, \\ Moshtohor, Toukh, 13736 Qalioubeya, Egypt
}

* Author to whom correspondence should be addressed; E-Mail: julia.schumann@vmf.uni-leipzig.de; Tel.: +49-341-9738-107; Fax: +49-341-9738-119.

Received: 26 March 2013; in revised form: 15 April 2013 / Accepted: 18 April 2013 /

Published: 25 April 2013

\begin{abstract}
The impact of polyunsaturated fatty acid (PUFA) supplementation on phospholipase D (PLD) trafficking and activity in mast cells was investigated. The enrichment of mast cells with different PUFA including $\alpha$-linolenic acid (LNA), eicosapentaenoic acid (EPA), docosahexaenoic acid (DHA), linoleic acid (LA) or arachidonic acid (AA) revealed a PUFA-mediated modulation of the mastoparan-stimulated PLD trafficking and activity. All PUFA examined, except AA, prevented the migration of the PLD1 to the plasma membrane. For PLD2 no PUFA effects on trafficking could be observed. Moreover, PUFA supplementation resulted in an increase of mastoparan-stimulated total PLD activity, which correlated with the number of double bonds of the supplemented fatty acids. To investigate, which PLD isoform was affected by PUFA, stimulated mast cells were supplemented with DHA or AA in the presence of specific PLD-isoform inhibitors. It was found that both DHA and AA diminished the inhibition of PLD activity in the presence of a PLD1 inhibitor. By contrast, only AA diminished the inhibition of PLD activity in the presence of a PLD2 inhibitor. Thus, PUFA modulate the trafficking and activity of PLD isoforms in mast cells differently. This may, in part, account for the immunomodulatory effect of unsaturated fatty acids and contributes to our understanding of the modulation of mast cell activity by PUFA.
\end{abstract}


Keywords: phospholipase D; polyunsaturated fatty acids; mast cells; exocytosis

\section{Introduction}

Polyunsaturated fatty acids (PUFA) of the n3- and the n6-family are incorporated into cellular membranes directly or after metabolism and influence membrane properties. We have demonstrated in a previous study that the enrichment of the culture medium of $\mathrm{C} 2$ mast cells with $\alpha$-linolenic acid (LNA), eicosapentaenoic acid (EPA), docosahexaenoic acid (DHA), linoleic acid (LA) or arachidonic acid (AA) results in an increase in the content of these fatty acids both in raft and non-raft membrane domains [1]. The PUFA-mediated modulation of the lipid composition and the physiological properties of mast cell membrane microdomains are likely to impact mast cell function. In fact, alterations in membrane lipids have already been shown to affect the exocytosis of preformed mediators (e.g., histamine) and the release of newly synthesized lipid mediators (eicosanoids) by mast cells [2,3].

The mechanism with which PUFA modulate exocytosis and vesicle fusion is not yet well understood. It is known that the enzyme phospholipase D (PLD) is involved in regulating exocytosis and vesicle trafficking [4]. PLD catalyzes the hydrolysis of phosphatidylcholine (PC), a major phospholipid of membranes, to phosphatidic acid and choline [4]. Since the ubiquitous enzyme is regulated by a variety of hormones, neurotransmitters, growth factors, cytokines, and other molecules involved in cellular communication, PLD is believed to play an important role in signal transduction of many cell types including mast cells [5]. Two mammalian PLD isoforms have been described, PLD1 and PLD2 [4]. PLD1 exhibits a variable pattern of subcellular steady-state localization. In mast cells, PLD1 co-localizes with secretory vesicles and translocates to the plasma membrane upon stimulation [6,7]. PLD2 is reported to have a different subcellular distribution, being localized predominantly at the plasma membrane regardless of cellular stimulation $[4,8]$.

Several studies have discussed a modulating effect of PUFA on cellular PLD localization and activity. In COS-1 cells PUFA supplementation has been shown to affect the intracellular trafficking of PLD and its activity due to alterations in the membrane lipid environment [9]. In human lymphocytes a stimulatory effect of DHA and hydroxyeicosatetraenoic acid, a derivative of AA, on total PLD activity has also documented [10,11]. Other studies have demonstrated PLD-dependent effects of fatty acids in neutrophils [12], smooth muscle cells [13] and macrophages [14]. However, so far there are no data on the impact of PUFA on PLD translocation and activity in mast cells regarding the isoforms PLD1 and PLD2.

The present study was undertaken to elucidate the nature of the PUFA influence on mast cell PLD1 and PLD2 localization and activity. The enlightenment of this will further our understanding of the regulation of the exocytosis of inflammatory mediators by mast cells. The study can provide new avenues for the treatment of diseases characterized by dysregulated secretory mast cell events. 


\section{Results and Discussion}

\subsection{Distribution of PLD Isoforms in C2 Mast Cells with Regard to Stimulation Status}

To elucidate the localization of PLD1 and PLD2 in mast cells, C2 cells were transiently transfected with GFP-tagged PLD1 or PLD2 fusion plasmids.

In unstimulated C2 mast cells, PLD1 was situated within intracellular vesicular structures (Figure 1a) whereas PLD2 was located at the plasma membrane (Figure 1c). For mast cell stimulation the cationic tetradecapeptide mastoparan was used [15]. After mastoparan stimulation PLD1 migrated to the plasma membrane (Figure 1b). In contrast, PLD2 localization was not affected by the stimulation (Figure 1d).

Figure 1. Localization of GFP-tagged PLD1 (a and b) and PLD2 (c and d) in transiently transfected C2 mast cells before (a and c) and after (b and d) stimulation with mastoparan $(25 \mu \mathrm{M})$. Cells were transfected using Turbofect transfection reagent and analyzed $24 \mathrm{~h}$ after transfection. Cells were scanned by confocal microscopy (TCS SP5 STED) using a x63 oil immersion Apochromat lens (all Leica Microsystems, Mannheim, Germany). Representative figures of $N=3, n=2$ examinations are shown.
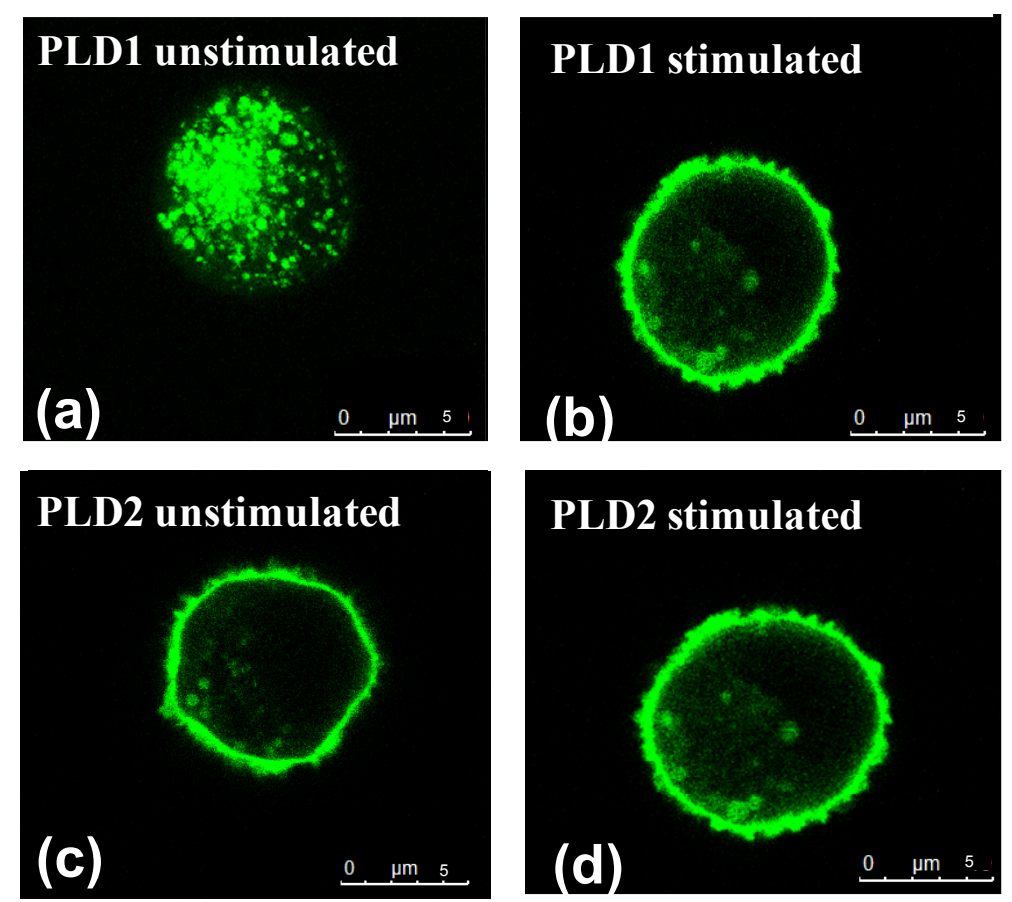

The results are in accordance with earlier studies conducted with the mast cell line RBL-2H3 [16] as well as with CHO cells [17], HL60 cells [18] and COS-1 cells [9], in which PLD1 was shown to be located intracellularly and found to translocate upon stimulation, while PLD2 was found at the plasma membrane regardless of cellular activation status.

\subsection{Influence of PUFA on Distribution of PLD Isoforms with Regard to Stimulation Status}

Using C2 transiently transfected with PLD1 or PLD2, the influence of PUFA on the distribution of PLD1 and PLD2 respectively was investigated. 
We have previously shown that supplementation of C2 mast cells with LNA, EPA, DHA, LA or AA results in an incorporation of the PUFA into the cell membrane [1], and is likely to modify the composition of membrane-mediated signaling molecules as phosphatidylinositol-4,5-bisphosphate (PIP2). However, PUFA supplementation of the culture medium did not affect the intracellular localization of PLD1 in vesicular structures of unstimulated C2 mast cells in this study. We found that PUFA enrichment completely abolished the stimulator-induced translocation of the PLD1 to the plasma membrane in mastoparan-stimulated cells, with the exception of AA (Figure 2). There was no effect of PUFA supplementation on the localization of the PLD2 in either unstimulated or stimulated C2 mast cells (data not shown). In addition, no influence of the solvent used for fatty acids application (ethanol) could be observed, since both PLD isoforms behaved in a similar manner in cells cultured in medium with or without ethanol (data not shown).

Figure 2. Localization of GFP-tagged PLD1 in transiently transfected C2 mast cells before $(\mathbf{a}, \mathbf{c}, \mathbf{e}, \mathbf{g}, \mathbf{i})$ and after $(\mathbf{b}, \mathbf{d}, \mathbf{f}, \mathbf{h}, \mathbf{j})$ stimulation with mastoparan $(25 \mu \mathrm{M})$. Cells were transfected using Turbofect transfection reagent and analyzed $24 \mathrm{~h}$ after transfection. Cell culture medium was enriched for 8 days with one of the following PUFA in a concentration of $20 \mu \mathrm{mol} / \mathrm{L}$ : $\alpha$-linoleic acid (LNA; $\mathbf{a}$ and b), eicosapentaenoic acid (EPA; $\mathbf{c}$ and d), docosahexaenoic acid (DHA; e and $\mathbf{f}$ ), linoleic acid (LA; $\mathbf{g}$ and $\mathbf{h}$ ), arachidonic acid (AA; $\mathbf{i}$ and $\mathbf{j}$ ). Cells were scanned by means of confocal microscopy (TCS SP5 STED) using a x63 oil immersion Apochromat lens (all Leica Microsystems, Mannheim, Germany). Representative figures of $N=3, n=2$ examinations are shown.
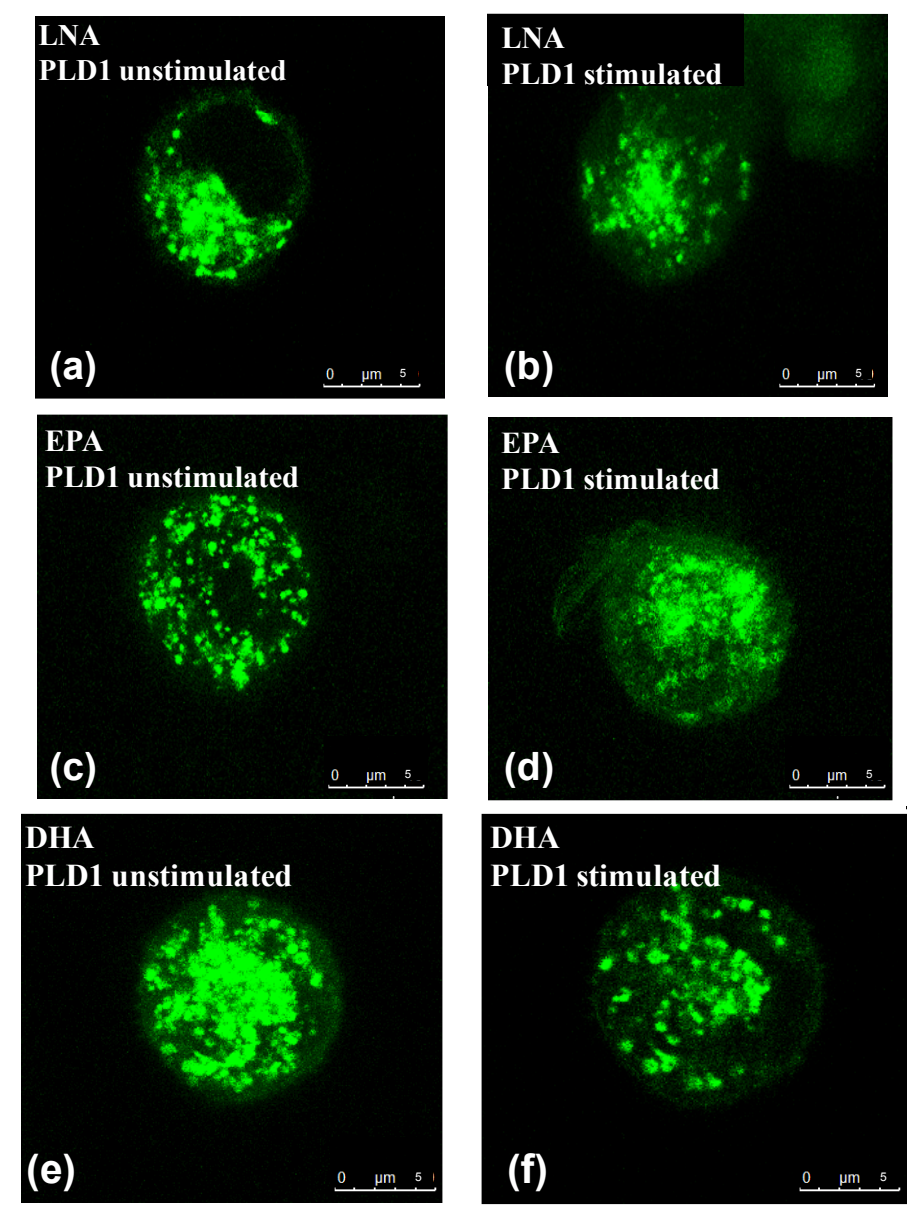
Figure 2. Cont.
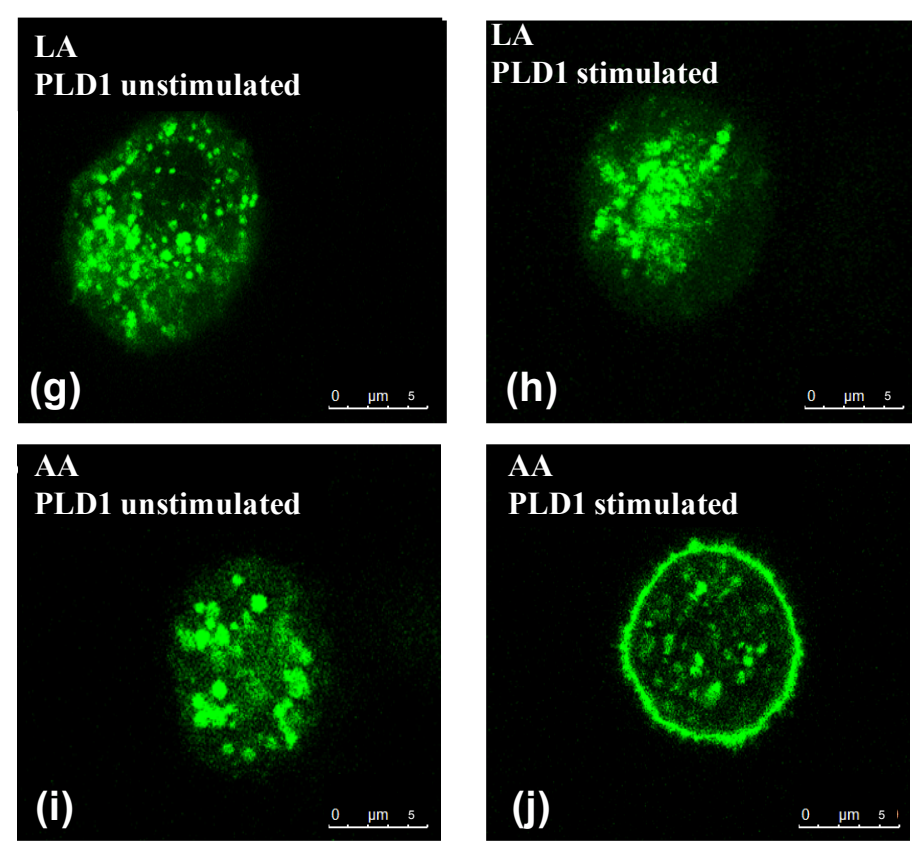

The divergent effects of PUFA on PLD1 translocation found here may be due to their differing action on the translocation-mediating signaling molecules. Mastoparan activates trimeric $\mathrm{G}$ proteins $[19,20]$ and increases intracellular $\mathrm{Ca}^{2+}$ [21,22], which is important for the activation of the protein kinase $\mathrm{C} \alpha$ (PKC $\alpha$ ) [23]. PKC $\alpha$ and PLD1 are co-localized [24,25] and are translocated to the plasma membrane upon $\mathrm{Ca}^{2+}$-mediated activation of PKCa [26-28]. For EPA and DHA it has been shown that these PUFA inhibit the stimulation-mediated translocalization of PKC $\alpha[29,30]$. As PKC $\alpha$ and PLD1 are translocated together, it is possible that the inhibition of PKC $\alpha$ by EPA and DHA leads to the inhibition of PLD1 translocation observed in our study. In contrast, AA has been described as a direct activator of PKC $\alpha$ [31,32] and thus does not prevent PLD1 translocation in mastoparan-stimulated mast cells. Until now, there are no data on the effects of LA and LNA on PKCa. However, based on the data presented here we suggest that LA and LNA mediate the inhibition of PLD1 translocation as EPA and DHA via a suppression of PKC $\alpha$ activity.

\subsection{Influence of PUFA Supplementation on Total PLD Activity}

In addition to investigating the impact of PUFA on PLD localization, we intended to explore PUFA-mediated effects on PLD activity. As an initial step, we assessed the consequences of a PUFA supplementation of $\mathrm{C} 2$ mast cells for eight days on total PLD activity.

Total PLD exhibited low basal activity in unstimulated C2 mast cells regardless whether and which PUFA was supplemented (Figure 3). Stimulation of the mast cells with mastoparan significantly increased the total PLD activity (Figure 3). The stimulation-induced increase in total PLD activity was evident with and without PUFA supplementation (Figure 3). However, enrichment of the C2 mast cells with LNA, EPA, DHA, LA and AA respectively further increased the total PLD activity of the cells (Figure 3). At this, the PUFA-mediated increase in total PLD activity positively correlated with the number of double bonds of the supplemented fatty acids. 
Figure 3. Total PLD activity of C2 mast cells. Cells were cultured for 8 days in basic medium (control) as well as in medium supplemented with $20 \mu \mathrm{mol} / \mathrm{L}$ of either alpha-linolenic acid (LNA), eicosapentaenoic acid (EPA), docosahexaenoic acid (DHA), linoleic acid (LA) or arachidonic acid (AA). Cells were labeled with $\left[{ }^{3} \mathrm{H}\right]$ myristic acid for $24 \mathrm{~h}$ and stimulated with mastoparan $(25 \mu \mathrm{M})$ in the presence of $0.5 \%$ n-butanol for $30 \mathrm{~min}$. Data are mean $\pm \operatorname{SD}(N=3, n=4)$. Bars of one color denoted by different letters are significantly different.

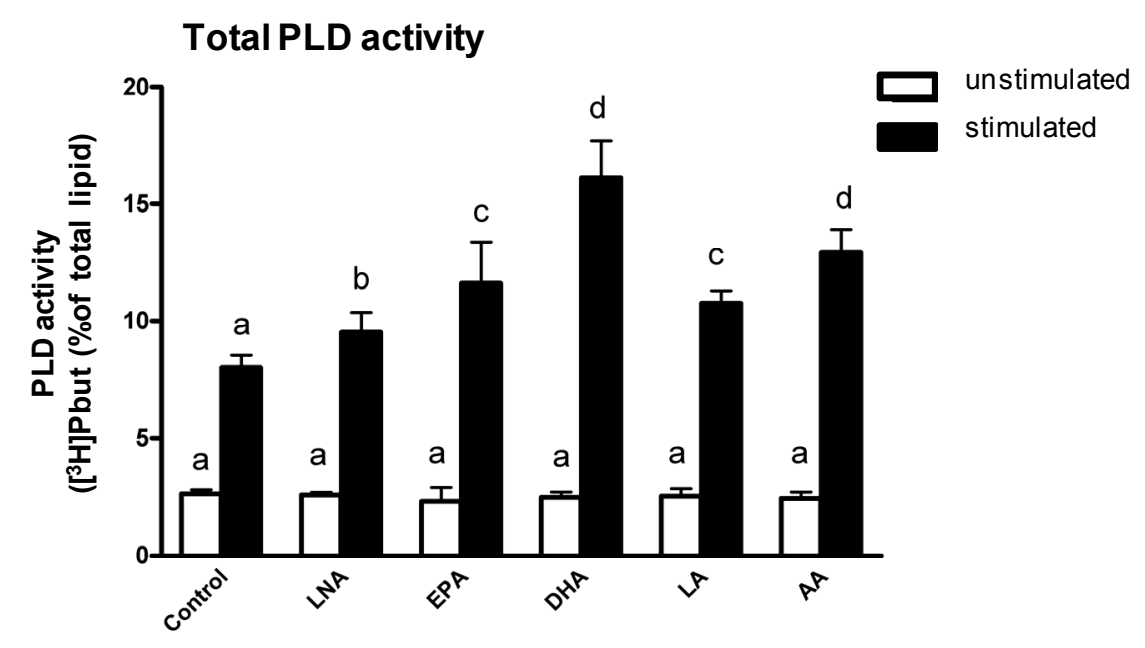

Our data are in accordance with previous studies using COS-1 [9] cells and peripheral blood mononuclear cells [10], which also documented that PUFA can increase the stimulation-induced total PLD activity. However, the data obtained in the present study demonstrate for the first time that PUFA enhance total PLD activity in mast cells. Thus, we provide first evidence that the modulation of mast cell signaling, vesicular trafficking and membrane transport by PUFA [2,3] might be at least in part due to a PUFA-mediated increase of total PLD activity. It is interesting to note that despite the divergent actions of AA and the other PUFA tested on PLD1 translocation there were similar effects of all PUFA tested on total PLD activity. This supports the notion that PLD translocation and PLD activity may not be linked to one another other. The most likely cause for this can be seen in the divergent mediators, which bring about PLD1 translocation and total PLD activity. Note that the stimulation of total PLD activity is under the control of the ADP-ribosylation factor (ARF), the GTPase Rho, the phospholipid phosphatidylinositol 4,5-bisphosphate (PIP2) as well as the PKC $\alpha$ [8,33] whereas PLD1 translocation is mediated by PKC $\alpha$ only $[24,25]$.

\subsection{Dose Response Curves for PLD1 and PLD2 Inhibitors}

To find out which of the two PLD isoforms is implicated in the PUFA-mediated increase in total PLD activity, PLD activity was measured in the presence of specific PLD1 or PLD2 inhibitors (VU0155069 [34] and VU0364739 HCL [35], respectively). However, since the inhibitors have not been used in C2 mast cells so far, a dose response curve of each inhibitor was determined. In accordance to the literature for C2 mast cells a selective inhibition of PLD1 and PLD2 by VU0155069 and VU0364739 HCL was found (Figure 4). The recommended dose of either PLD1 or PLD2 inhibitors resulted in a nearly $60 \%$ inhibition of PLD1 or PLD2 in our mast cell line (Figure 4). 
Figure 4. Dose response curves for PLD1 and PLD2 inhibitors. C2 mast cells were treated with different concentrations of a PLD1 (a) or a PLD2 (b) inhibitor. Cells were labeled with $\left[{ }^{3} \mathrm{H}\right]$ myristic acid for $24 \mathrm{~h}$ and stimulated by mastoparan $(25 \mu \mathrm{M})$ in the presence of $0.5 \% n$-butanol for $30 \mathrm{~min}$. Data are mean $\pm \mathrm{SD}(n=3)$.

(a)

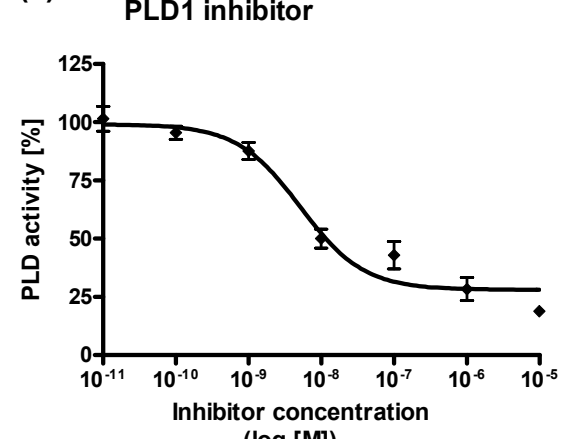

$(\log [\mathrm{M}])$ (b)

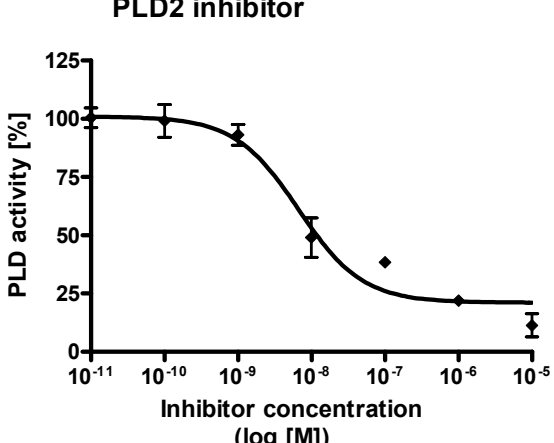

$(\log [\mathrm{M}])$

\subsection{Influence of PUFA Supplementation on the Activity of PLD Isoforms}

Using the PLD2 inhibitor VU0364739 HCL or the PLD1 inhibitor VU0155069 the influence of DHA and AA on the activity of the PLD isoforms PLD1 and PLD2 was determined.

No PUFA effects on unstimulated mast cells were observed in presence of the inhibitors (Figure 5). Stimulation of the $\mathrm{C} 2$ mast cells with mastoparan resulted in a significant increase in PLD activity in presence of both the PLD2 inhibitor and the PLD1 inhibitor (Figure 5). However, different effects of PUFA supplementation on stimulated mast cells could be seen. Remarkably, the decrease in PLD activity in the presence of the PLD2 inhibitor was significantly less with AA in comparison to DHA supplementation (Figure 5a). In presence of the PLD1 inhibitor the decreasing effect on PLD activity was diminished by both PUFA examined (Figure $5 b$ ).

The differential impact of AA and DHA in the presence of either a PLD2 or a PLD1 inhibitor may be due to the different activation factors of PLD1 and PLD2. Besides the common activators of both PLD1 and PLD2, namely ARF and PIP2, there are also isoform-specific PLD regulatory proteins [4]. PLD1 is selectively activated by the GTPases Rho, Rac1 and Cdc42 as well as the PKC $\alpha$ [4]. PLD2 is selectively activated by the GTPase Rac2 as well as the Src kinase [4]. Studies have shown that AA mediates the activation of ARF, Rho and PKC $\alpha$ [36,37]. This might explain the diminishing effect of AA on PLD inhibition in presence of both PLD inhibitors. For DHA the situation is different, however. On the one hand, DHA has been reported to promote ARF [11]. On the other hand, DHA has been demonstrated to down-regulate the expression of Rho and to inhibit PKC $\alpha[38,39]$. In addition, it is well documented that DHA induces a significant movement of Src out of the lipid rafts thereby promoting PLD2 activity [40]. Presumably, the divergent effects of DHA on PLD1-activating mediators complement each other and lead to a diminishing effect of DHA on the inhibitor-induced decrease in PLD activity in presence of a PLD1 inhibitor only. 
Figure 5. PLD activity of C2 mast cells in presence of a PLD2 (a) or a PLD1 (b) inhibitor. Cells were cultured for 8 days in basic medium (control) as well as in medium supplemented with $20 \mu \mathrm{mol} / \mathrm{L}$ of either alpha-linolenic acid (LNA), eicosapentaenoic acid (EPA), docosahexaenoic acid (DHA), linoleic acid (LA) or arachidonic acid (AA). Cells were labeled with ${ }^{3}[\mathrm{H}]$ myristic acid for $24 \mathrm{~h}$ and stimulated by mastoparan $(25 \mu \mathrm{M})$ in the presence of $0.5 \% n$-butanol for $30 \mathrm{~min}$. Data are mean $\pm \operatorname{SD}(N=3, n=4)$. Bars of one color denoted by different letters are significantly different.

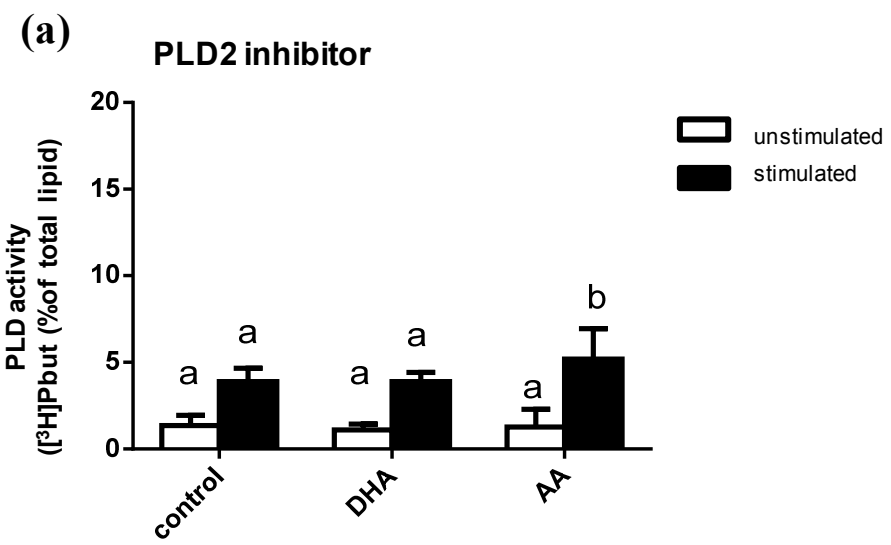

(b) PLD1 inhibitor

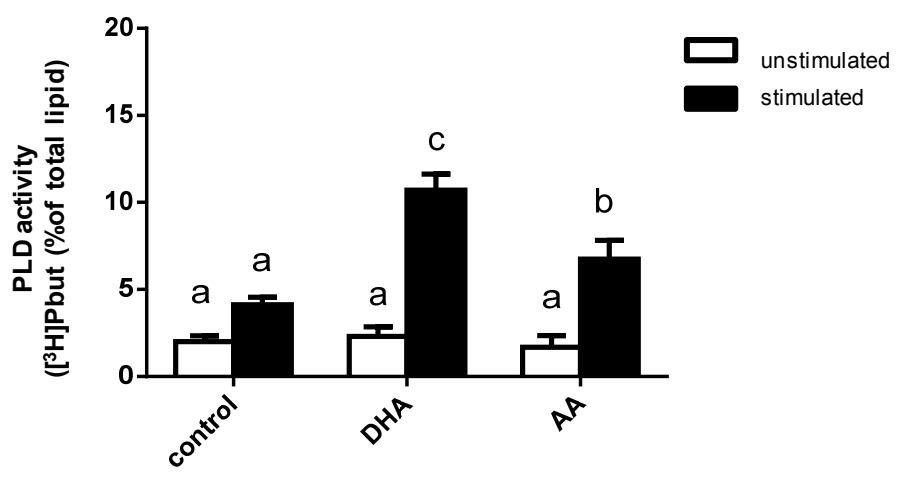

\section{Experimental Section}

\subsection{Materials}

All chemicals and reagents were obtained from Sigma-Aldrich (Taufkirchen, Germany) unless noted otherwise. Cell culture flasks were purchased from Greiner Bio-One (Frickenhausen, Germany). Dulbecco's modified Eagle's medium /HAMs F12 1:1 containing 0.14 $\mu \mathrm{mol} / \mathrm{L}$ LA was obtained from Biochrome KG (Berlin, Germany) and Rotiszint ${ }^{\circledR}$ eco plus from Carl Roth (Karlsruhe, Germany). Silica gel 60 TLC plates were purchased from Merck Millipore (Darmstadt, Germany). [ $\left.{ }^{3} \mathrm{H}\right]$ Myristic acid was purchased from PerkinElmer LAS GmbH (Rodgau, Germany).

\subsection{Cell Culture}

The permanent canine mastocytoma cell line $\mathrm{C} 2$ was used. The cell line stems from isolated canine mastocytoma tumor cells, which were passaged serially 30-50 times in athymic nude mice [41,42]. The characteristics of the cell line used are comparable with other mast cell preparations like human 
lung mast cells, peritoneal or bone marrow-derived mast cells of rats $[41,42] .1 .25 \times 10^{7}$ cells were cultured in $75 \mathrm{~cm}^{2}$ flasks using DMEM/HAM's F12 (1:1) medium supplemented with $2 \mathrm{mM}$ glutamine, $25 \mathrm{mM}$ HEPES (pH 7.4), $1.6 \mathrm{mM}$ histidine, $100 \mathrm{U} / \mathrm{mL}$ penicillin, $100 \mu \mathrm{g} / \mathrm{mL}$ streptomycin, $5 \%$ FCS and $5 \mu \mathrm{mol} / \mathrm{L} \alpha$-tocopherol. To investigate the influence of PUFA, one of the following fatty acids was included in the culture medium at a concentration of $20 \mu \mathrm{mol} / \mathrm{L}$ using ethanol as a vehicle: $\alpha$-linolenic acid (C18:3n3, LNA), eicosapentaenoic acid (C20:5n3, EPA), docosahexaenoic acid (C22:6n3, DHA), linoleic acid (C18:2n6, LA) or arachidonic acid (C20:4n6, AA) (all Biotrend, Köln, Germany). Final ethanol concentration was $0.1 \% \quad v / v$. Cells cultured in medium without PUFA supplementation but containing $0.1 \%$ ethanol were used as control. Cells were incubated for 8 days at $37^{\circ} \mathrm{C}$ and $5 \% \mathrm{CO}_{2}$ in a humidified atmosphere.

\subsection{Transient Transfection}

Transient transfection of C2 mast cells with pEGFP-hPLD1 and pEGFP-mPLD2 green fluorescent fusion plasmids respectively (kindly supplied by Prof. Shamshad Cockroft, Department of Physiology, University College London) was performed using chicken egg white coated 12-well plates as previously described [43]. Briefly, $22 \mathrm{~mm}^{2}$ surface area/well were covered with chicken egg white $(0.75 \mathrm{~mL} /$ well $)$ and carefully heated on a heat block at $58{ }^{\circ} \mathrm{C}$. After $60 \mathrm{~min}$, the egg white became semi-solid and adhered to the bottom of the wells. Excess egg white was washed out using PBS. The C2 cells were seeded at $5 \times 10^{5}$ cells/well and transfected with Turbofect transfection reagent (Fermentas, Sankt Leon Rot, Germany) according to the manufacturer's instructions and incubated for $24 \mathrm{~h}$ before analysis.

\subsection{Confocal Microscopy}

Evaluation of PLD1 and PLD2 localization was performed using a TCS SP5 STED microscope (Leica Microsystems, Mannheim, Germany). GFP was excited at $488 \mathrm{~nm}$, and green fluorescence was detected at $595 \mathrm{~nm}$. Data analysis was performed using the Leica confocal software LeicaLight version 2.61 (Leica confocal software: Mannheim, Germany, 2008).

\subsection{Measurement of PLD Activity}

PLD activity was assessed by measuring the PLD reaction product $\left[{ }^{3} \mathrm{H}\right]$ phosphatidylbutanol (PBut) as described by Sarri and co-workers [16] with some modifications. Briefly, C2 cells were seeded at $6 \times 10^{5} /$ well in 12 -well plates and were labeled with $\left[{ }^{3} \mathrm{H}\right]$ myristic acid for $24 \mathrm{~h}$ at $37{ }^{\circ} \mathrm{C}$ in DMEM medium. Afterwards $\left[{ }^{3} \mathrm{H}\right]$ myristic acid was washed out and the cells were stimulated with mastoparan $(25 \mu \mathrm{M})$ in Hepes buffer in the presence of $0.5 \% \mathrm{n}$-butanol for $30 \mathrm{~min}$. Stimulation was terminated by adding $0.5 \mathrm{~mL}$ of ice-cold methanol/ $\mathrm{HCl}(98: 2, v / v)$. Cells were lysed with $500 \mu \mathrm{L}$ methanol. Two phases were generated by adding $1 \mathrm{~mL}$ of chloroform and $1 \mathrm{~mL}$ of water. After vortexing, $900 \mu \mathrm{L}$ were collected from the chloroform phase, and the chloroform was evaporated with a gentle nitrogen stream. Remaining lipids were solved in $20 \mu \mathrm{L}$ of chloroform and spotted on a silica gel 60 TLC plate. Lipids were separated with the solvent system chloroform/methanol/acetic acid/water $(9: 1: 0.3: 0.04, v / v)$. The lanes corresponding to the PLD reaction product $\left[{ }^{3} \mathrm{H}\right] \mathrm{PBut}$ were identified with 
authentic standards after iodine staining, scraped and counted for radioactivity. Data were expressed as the ratio of $\left[{ }^{3} \mathrm{H}\right] \mathrm{PBut}$ to $\left[{ }^{3} \mathrm{H}\right]$ total lipids.

\subsection{Selective Inhibition of PLD Isforms}

C2 cells were labeled with $\left[{ }^{3} \mathrm{H}\right]$ myristic acid as described above. Labeled cells were stimulated with mastoparan $(25 \mu \mathrm{M})$ in the presence of the PLD1 inhibitor VU0155069 (Cayman Chemical Company, Ann Arbor, MI, USA) or the PLD2 inhibitor VU0364739 HCL (Tocris Bioscience, Bristol, UK) in HEPES buffer in the presence of $0.5 \% \mathrm{n}$-butanol for $30 \mathrm{~min}$. Concentrations of inhibitors used were a) $10^{-11}-10^{-5} \mathrm{M}$ for dose response curves b) $11 \mathrm{nM}$ for the PLD1 inhibitor and $20 \mathrm{mM}$ for the PLD2 inhibitor for determination of PUFA effects on PLD isoform activity. Measurement of PLD activity was performed as described above.

\subsection{Statistical Analysis}

Data are shown as means with standard deviation (SD). A two-way analysis of variance followed by unpaired Students $t$ test was used to identify significant differences between means. The statistical analysis was carried out with GraphPad Prism 4 (GaphPad Software, La Jolla, CA, USA). In all cases $p<0.05$ was assumed to indicate significant differences. The transient transfection was performed in duplicates in three independent experiments. The measurement of total PLD activity as well as the selective inhibition of PLD isoforms was performed in quadruples in three independent experiments.

\section{Conclusions}

Although phospholipases and PUFA have been known to play a crucial role in exocytosis for several decades, we are still lacking a complete picture of their mode of action. The present study showed that PUFA differentially modulate the trafficking and the activity of PLD isoforms in mast cells. All PUFA examined, except AA, prevented the translocation of the PLD1 within intracellular vesicular structures to the plasma membrane. For PLD2 no effects of PUFA on trafficking could be observed. Moreover, PUFA supplementation resulted in an increase of mastoparan-stimulated total PLD activity. At this, both DHA and AA diminished the inhibition of PLD activity in the presence of a PLD1 inhibitor but only AA diminished the inhibition of PLD activity in the presence of a PLD2 inhibitor. These differential effects of PUFA may, in part, account for the immunomodulatory effect of these fatty acids and contribute to our understanding of the PUFA-mediated modulation of mast cell activity.

\section{Acknowledgments}

We gratefully acknowledge Shamshad Cockcroft for providing pEGFP-hPLD1 and pEGFP-mPLD2 fusion plasmids with the kind permission of Michael A. Frohman. We thank Barbara Goettgens for her technical assistance with the confocal laser scanning microscope. We would further like to thank the DAAD (German Academic Exchange Service) for financial support of S.B., grant no. A/09/92498. 


\section{Conflict of Interest}

The authors declare no conflict of interest.

\section{References}

1. Basiouni, S.; Stockel, K.; Fuhrmann, H.; Schumann, J. Polyunsaturated fatty acid supplements modulate mast cell membrane microdomain composition. Cell. Immunol. 2012, 275, 42-46.

2. Gueck, T.; Seidel, A.; Fuhrmann, H. Effects of essential fatty acids on mediators of mast cells in culture. Prostaglandins Leukot. Essent. Fat. Acids 2003, 68, 317-322.

3. Gueck, T.; Seidel, A.; Baumann, D.; Meister, A.; Fuhrmann, H. Alterations of mast cell mediator production and release by gamma-linolenic and docosahexaenoic acid. Vet. Dermatol. 2004, 15, 309-314.

4. Selvy, P.E.; Lavieri, R.R.; Lindsley, C.W.; Brown, H.A. Phospholipase D: Enzymology, functionality, and chemical modulation. Chem. Rev. 2011, 111, 6064-6119.

5. Exton, J.H. New developments in phospholipase D. J. Biol. Chem. 1997, 272, 15579-15582.

6. Brown, F.D.; Thompson, N.; Saqib, K.M.; Clark, J.M.; Powner, D.; Thompson, N.T.; Solari, R.; Wakelam, M.J.O. Phospholipase D1 localises to secretory granules and lysosomes and is plasma-membrane translocated on cellular stimulation. Curr. Biol. 1998, 8, 835-838.

7. Choi, W.S.; Kim, Y.M.; Combs, C.; Frohman, M.A.; Beaven, M.A. Phospholipases D1 and D2 regulate different phases of exocytosis in mast cells. J. Immunol. 2002, 168, 5682-5689.

8. Colley, W.C.; Sung, T.C.; Roll, R.; Jenco, J.; Hammond, S.M.; Altshuller, Y.; BarSagi, D.; Morris, A.J.; Frohman, M.A. Phospholipase D2, a distinct phospholipase D isoform with novel regulatory properties that provokes cytoskeletal reorganization. Curr. Biol. 1997, 7, 191-201.

9. Gemeinhardt, A.; Alfalah, M.; Guck, T.; Naim, H.Y.; Fuhrmann, H. The influence of linoleic and linolenic acid on the activity and intracellular localisation of phospholipase D in COS-1 cells. Biol. Chem. 2009, 390, 253-258.

10. Bechoua, S.; Dubois, M.; Nemoz, G.; Lagarde, M.; Prigent, A.F. Docosahexaenoic acid lowers phosphatidate level in human activated lymphocytes despite phospholipase D activation. J. Lipid Res. 1998, 39, 873-883.

11. Diaz, O.; Berquand, A.; Dubois, M.; di Agostino, S.; Sette, C.; Bourgoin, S.; Lagarde, M.; Nemoz, G.; Prigent, A.F. The mechanism of docosahexaenoic acid-induced phospholipase D activation in human lymphocytes involves exclusion of the enzyme from lipid rafts. J. Biol. Chem. 2002, 277, 39368-39378.

12. Grenier, S.; Flamand, N.; Pelletier, J.; Naccache, P.H.; Borgeat, P.; Bourgoin, S.G. Arachidonic acid activates phospholipase $\mathrm{D}$ in human neutrophils; essential role of endogenous leukotriene B-4 and inhibition by adenosine A(2A) receptor engagement. J. Leukoc. Biol. 2003, 73, 530-539.

13. Askari, B.; Carroll, M.A.; Capparelli, M.; Kramer, F.; Gerrity, R.G.; Bornfeldt, K.E. Oleate and linoleate enhance the growth-promoting effects of insulin-like growth factor-I through a phospholipase D-dependent pathway in arterial smooth muscle cells. J. Biol. Chem. 2002, 277, 36338-36344.

14. Wang, Y.T.; Oram, J.F. Unsaturated fatty acids phosphorylate and destabilize ABCA1 through a phospholipase D2 pathway. J. Biol. Chem. 2005, 280, 35896-35903. 
15. Chahdi, A.; Choi, W.S.; Kim, Y.M.; Beaven, M.A. Mastoparan selectively activates phospholipase D2 in cell membranes. J. Biol. Chem. 2003, 278, 12039-12045.

16. Sarri, E.; Pardo, R.; Fensome-Green, A.; Cockcroft, S. Endogenous phospholipase D2 localizes to the plasma membrane of RBL-2H3 mast cells and can be distinguished from ADP ribosylation factor-stimulated phospholipase D1 activity by its specific sensitivity to oleic acid. Biochem. J. 2003, 369, 319-329.

17. Emoto, M.; Klarlund, J.K.; Waters, S.B.; Hu, V.; Buxton, J.M.; Chawla, A.; Czech, M.P. A role for phospholipase D in GLUT4 glucose transporter translocation. J. Biol. Chem. 2000, 275, 7144-7151.

18. Whatmore, J.; Morgan, C.P.; Cunningham, E.; Collison, K.S.; Willison, K.R.; Cockcroft, S. ADP-ribosylation factor 1-regulated phospholipase D activity is localized at the plasma membrane and intracellular organelles in HL60 cells. Biochem. J. 1996, 320, 785-794.

19. Ross, E.M.; Higashijima, T. Regulation of G-protein activation by mastoparans and other cationic peptides. Methods Enzymol. 1994, 237, 26-37.

20. Higashijima, T.; Burnier, J.; Ross, E.M. Regulation of Gi and Go by mastoparan, related amphiphilic peptides, and hydrophobic amines-Mechanism and structural determinants of activity. J. Biol. Chem. 1990, 265, 14176-14186.

21. Dedos, S.G.; Wicher, D.; Kaltofen, S.; Birkenbeil, H. Different $\mathrm{Ca}^{2+}$ signalling cascades manifested by mastoparan in the prothoracic glands of the tobacco hornworm, Manduca sexta, and the silkworm, Bombyx mori. Arch. Insect Biochem. Physiol. 2007, 65, 52-64.

22. Nakahata, N.; Ishimoto, H.; Mizuno, K.; Ohizumi, Y.; Nakanishi, H. Dual effects of mastoparan on intracellular free $\mathrm{Ca}^{2+}$ concentrations in human astrocytoma-cells. Br. J. Pharmacol. 1994, 112, 299-303.

23. Tobio, A.; Alfonso, A.; Botana, L.M. c-kit mutations and PKC crosstalks: PKC translocates to nucleous only in cells HMC560,816. J. Cell. Biochem. 2011, 112, 2637-2651.

24. Oka, M.; Kageshita, T.; Ono, T.; Goto, A.; Kuroki, T.; Ichihashi, M. Protein kinase C alpha associates with phospholipase D-1 and enhances basal phospholipase D activity in a protein phosphorylationindependent manner in human melanoma cells. J. Investig. Dermatol. 2003, 121, 69-76.

25. Lee, S.; Park, J.B.; Kim, J.H.; Kim, Y.; Kim, J.H.; Shin, K.J.; Lee, J.S.; Ha, S.H.; Suh, P.G.; Ryu, S.H. Actin directly interacts with phospholipase D, inhibiting its activity. J. Biol. Chem. 2001, 276, 28252-28260.

26. Garbi, M.; Rubinstein, S.; Lax, Y.; Breitbart, H. Activation of protein kinase C alpha in the lysophosphatidic acid-induced bovine sperm acrosome reaction and phospholipase D1 regulation. Biol. Reprod. 2000, 63, 1271-1277.

27. Hu, T.H.; Exton, J.H. Mechanisms of regulation of phospholipase D1 by protein kinase Ca. J. Biol. Chem. 2003, 278, 2348-2355.

28. Mochly-Rosen, D.; Henrich, C.J.; Cheever, L.; Khaner, H.; Simpson, P.C. A protein kinase C isozyme is translocated to cytoskeletal elements on activation. Cell Regul. 1990, 1, 693-706.

29. Nair, S.S.D.; Leitch, J.; Garg, M.L. N-3 polyunsaturated fatty acid supplementation alters inositol phosphate metabolism and protein kinase $\mathrm{C}$ activity in adult porcine cardiac myocytes. J. Nutr. Biochem. 2001, 12, 7-13.

30. Denys, A.; Hichami, A.; Khan, N.A. n-3PUFAs modulate T-cell activation via protein kinase C-alpha and -epsilon and the NF-kappa B signaling pathway. J. Lipid Res. 2005, 46, 752-758. 
31. Khan, W.A.; Blobe, G.C.; Hannun, Y.A. Arachidonic-acid and free fatty-acids as 2nd-messengers and the role of protein-kinase-C. Cell. Signal. 1995, 7, 171-184.

32. Lopez-Nicolas, R.; Lopez-Andreo, M.J.; Marin-Vicente, C.; Gomez-Fernandez, J.C.; Corbalan-Garcia, S. Molecular mechanisms of PKCalpha localization and activation by arachidonic acid. The $\mathrm{C} 2$ domain also plays a role. J Mol. Biol. 2006, 357, 1105-1120.

33. Divecha, N.; Roefs, M.; Halstead, J.R.; D’Andrea, S.; Fernandez-Borga, M.; Oomen, L.; Saqib, K.M.; Wakelam, M.J.; D'Santos, C. Interaction of the type Ialpha PIPkinase with phospholipase D: A role for the local generation of phosphatidylinositol 4, 5-bisphosphate in the regulation of PLD2 activity. EMBO J. 2000, 19, 5440-5449.

34. Lavieri, R.R.; Scott, S.A.; Selvy, P.E.; Kim, K.; Jadhav, S.; Morrison, R.I.; Daniels, J.S.; Brown, H.A.; Lindsley, C.W. Design, synthesis, and biological evaluation of halogenated N-(2-(4Oxo-1-phenyl-1,3,8-triazaspiro[4.5]decan-8-yl)ethyl)benzamides: Discovery of an isoform-selective small molecule phospholipase D2 inhibitor. J. Med. Chem. 2010, 53, 6706-6719.

35. Scott, S.A.; Selvy, P.E.; Buck, J.R.; Cho, H.P.; Criswell, T.L.; Thomas, A.L.; Armstrong, M.D.; Arteaga, C.L.; Lindsley, C.W.; Brown, H.A. Design of isoform-selective phospholipase D inhibitors that modulate cancer cell invasiveness. Nat. Chem. Biol. 2009, 5, 108-117.

36. Araki, S.; Ito, M.; Kureishi, Y.; Feng, J.H.; Machida, H.; Isaka, N.; Amano, M.; Kaibuchi, K.; Hartshorne, D.J.; Nakano, T. Arachidonic acid-induced $\mathrm{Ca}^{2+}$ sensitization of smooth muscle contraction through activation of Rho-kinase. Pflugers Arch.-Eur. J. Physiol. 2001, 441, 596-603.

37. Fu, X.; Gong, M.C.; Jia, T.; Somlyo, A.V.; Somlyo, A.P. The effects of the Rho-kinase inhibitor Y-27632 on arachidonic acid-, GTPgammaS-, and phorbol ester-induced $\mathrm{Ca}^{2+}$-sensitization of smooth muscle. FEBS Lett. 1998, 440, 183-187.

38. Young, C.; Gean, P.W.; Chiou, L.C.; Shen, Y.Z. Docosahexaenoic acid inhibits synaptic transmission and epileptiform activity in the rat hippocampus. Synapse 2000, 37, 90-94.

39. Yi, L.; Zhang, Q.Y.; Mi, M.T. Role of Rho GTPase in inhibiting metastatic ability of human prostate cancer cell line PC-3 by omega-3 polyunsaturated fatty acid. Ai Zheng 2007, 26, 1281-1286.

40. Duraisamy, Y.; Lambert, D.; O’Neill, C.A.; Padfield, P.J. Differential incorporation of docosahexaenoic acid into distinct cholesterol-rich membrane raft domains. Biochem. Biophys. Res. Commun. 2007, 360, 885-890.

41. Devinney, R.; Gold, W.M. Establishment of 2 Dog mastocytoma cell-lines in continuous culture. Am. J. Respir. Cell Mol. Biol. 1990, 3, 413-420.

42. Lazarus, S.C.; Mccabe, L.J.; Nadel, J.A.; Gold, W.M.; Leikauf, G.D. Effects of mast cell-derived mediators on epithelial-cells in canine trachea. Am. J. Physiol. 1986, 251, C387-C394.

43. Basiouni, S.; Fuhrmann, H.; Schumann, J. High-efficiency transfection of suspension cell lines. Biotechniques 2012, 1-4, doi:10.2144/000113914.

(C) 2013 by the authors; licensee MDPI, Basel, Switzerland. This article is an open access article distributed under the terms and conditions of the Creative Commons Attribution license (http://creativecommons.org/licenses/by/3.0/). 